\title{
DYNAMIC RESPONSE CONTROL OF SWING ROLLER FOLLOWER SYSTEM
}

\author{
NURUDEEN A. RAJI, KASALI A. ADEDEJI, JOSHUA O. OLALEYE AND ROTIMI O. OGUNLEYE
}

(Received 8 May 2019; Revision Accepted 9 January 2020)

\begin{abstract}
This paper studied the design of Proportional-Integral-Derivative (PID) control system for the attenuation of the residual vibration in the swing roller cam-follower system designed for horizontal narrow loom. The dynamic model for the system was developed and the PID controller coefficients were synthesized to ensure that the follower and beater systems behaved in a desired manner. The controller for the system is designed and implemented on the MATLAB ${ }^{\circledR}$ and Simulink ${ }^{\circledR}$. Basic concepts of feedback for closed-loop control regulators is used to maintain the system stability and to improve the system's performance using the classical structure of proportional, integral, and derivative controllers. The performance of the mechanism is assessed according to the extreme residual vibration amplitude value of the working links. The variation in the gains of the derivative controller was found to have substantial influence on the reduction rate of the residual vibration of the mechanism during operation.
\end{abstract}

KEYWORDS: Cam, mechanism, residual, vibration, modeling, control, feedback.

\section{INTRODUCTION}

The narrow horizontal weaving loom is one of the mechanisms widely used for weaving strip of clothes in the West African region. There have been several attempts in the past years towards the mechanization and automation of the loom for purpose of optimizing the production process and improving the productivity of the loom. The design, modeling and dynamical response of such system had be extensively discussed in Raji, (2000); Raji \& Adegbuyi, (2003); Raji, Erameh, Ozor, Ajayi \& Kuku, (2010); Raji, Ozor \& Kuku, (2011a); Raji, Erameh, Ajayi \& Kuku, (2011b) and the control of the system for optimum performance cannot be over emphasized.

Control is the process of manipulating, manually or automatically, the input of a dynamic system so that the system output will behave as desired (Esfandiari \& Lu, 2018). A swing roller cam follower mechanism was synthesized for the beat-up motion of the narrow horizontal weaving loom in Raji \& Adegbuyi, (2003) in which the profile of the plate cam and cutter coordinates equations were developed for exhibiting the beater motion of the mechanism allowing for shedding and shuttle motion of such mechanism.
In Raji et al. (2010) and Raji et al. (2011a), the analysis of the force requirement for the system showed that maximum impact required to beat the weft into the yarn during weaving was achieved at the maximum platecam displacement. The acceleration of the cam plate was controlled in the model at the start and end of motion as boundary conditions to specify some degree of stability for the system. However operation of the mechanism exposed the influence of the inertia forces arising from the system elements. A model was therefore developed to account to account for torsional and translational transmission of the mechanism towards improving its stability.

The modeling and response of the beater link attached to the swing roller follower for the operation of the beatup motion of a narrow loom was discussed in Raji, Durojaye \& Yussouff, (2016). The operation of the cam system for the narrow loom results in chaotic response for the beater link. Experimental investigation into such non-linear behavior of cam follower systems had earlier been discussed extensively in Abu-Mahfouz \& Badrakhan, (1990a) and (1990b) in which bifurcation pattern and its transition to chaotic behavior was explicitly analyzed. The vibratory character of the system is not unusual of mechanical systems due to the

Nurudeen A. Raji, Department of Mechanical Engineering, Lagos State University, Nigeria.

Kasali A. Adedeji, Department of Mechanical Engineering, Lagos State University, Nigeria.

Joshua O. Olaleye, Department of Mechanical Engineering, Lagos State University, Nigeria.

Rotimi O. Ogunleye, Krestfield Engineering Concept Ltd, Lagos. 
inertia and stiffness of its components. The chaotic response of the swing roller follower system was developed due to resonance when the operating speed of the mechanism attained the natural frequency of the system (Raji et al., 2016). Chaotic response causes complex follower motion which results from the adding and overlapping of different cycles of the vibration modes. The vibration of the system could be harmful to its smooth operation such that the intended function of the system is compromised. The need to control the excess vibration response of the beater link in the narrow loom beat up mechanism should therefore be a problem to focus on.

Various methods of suppressing vibration had been studied. Control forced method had been applied in the past for vibration suppression in multi degrees of freedom systems with damping (Ebrahimi, 1989). The method developed a non-linear optimization formulation for which a mathematical programming algorithm was used to solve the optimization problem numerically. Tsuji, Itoh, Ogasawara \& Mitsuta, (1995) used a linear programming approach for the design of feedback control system for a flexible structure in motion. The feedback gain for the feedback control system was obtained through optical regulatory theory. The study proposed a method of optimum vibration control for flexible structures. A special forcing function in the form of inverted cosine waves and ramped sinusoids had also been found to be effective in controlling the vibrations of mechanical systems (Nandy \& Sengupta, 1996).

Cam system vibration at resonance may be as a result of swift change in the mode of vibration of the cam system. This is usually caused by a jump in the mechanism or a separation of the cam and follower during operation (Ahirrao \& Khond, 2012). The speed at which the jump occur and preventing the system from attaining such speed could be a control method for avoiding vibration of the system due to the system's jump. A feed-forward and feedback method was proposed in Gatti, Mundo \& Danieli, (2007) for the control of cam follower system towards improving the dynamic performance of the cam-follower mechanism emphasizing on the follower acceleration.
The errors in cam profile manufacturing and variation in cam speed operation often result in tracking error which is the difference between the desired output response and the actual output response. Cam follower system output tracking error could be controlled using a repetitive control approach. The approach which is more suitable for a continuous cam follower process has been successfully applied in morphing a high-speed cam mechanism so that its output displacement tracks the desired output trajectory (Hirose et al., 2006). Optimization approach had been attempted by Singhose, (2009) in which the transient time of a system operation was minimized. However this does not favor optimal input function related to such system natural frequency causing the vibration. Also a time domain technique based on the generation of motion profiles with zero-crossing points in frequency spectra at the system resonances had been applied to reduce residual vibration in mechanical systems as discussed in Veciana \& Cardona, (2012).

The present study attempt to use the Proportional Integral Derivative (PID) control strategy for the control of the narrow loom cam follower system such as to minimize the residual vibration resulting during operation of the mechanism at high speed as is required of textile machinery mechanisms. The design of PID controller types for application in the control of dynamical systems had been extensively discussed in Aguilar-López \& Martinez-Guerra, (2007); Coelho \& Bernert, (2009); Kuo, Yau \& Pu, (2008); Hou, (2017); Yau, Hung \& Hsieh, (2012).

\section{MODELING AND CONTROL}

The degree of correlation between any physical situation and the mathematical model describing it depends upon how closely the model can be built to fit the physical situation. The swing roller follower designed for the beat up motion of a narrow loom is shown in Figure 2.1. A roller follower is assembled on a plate cam with a spring holding the follower in place ensuring continuous contact of the roller with the plate cam.

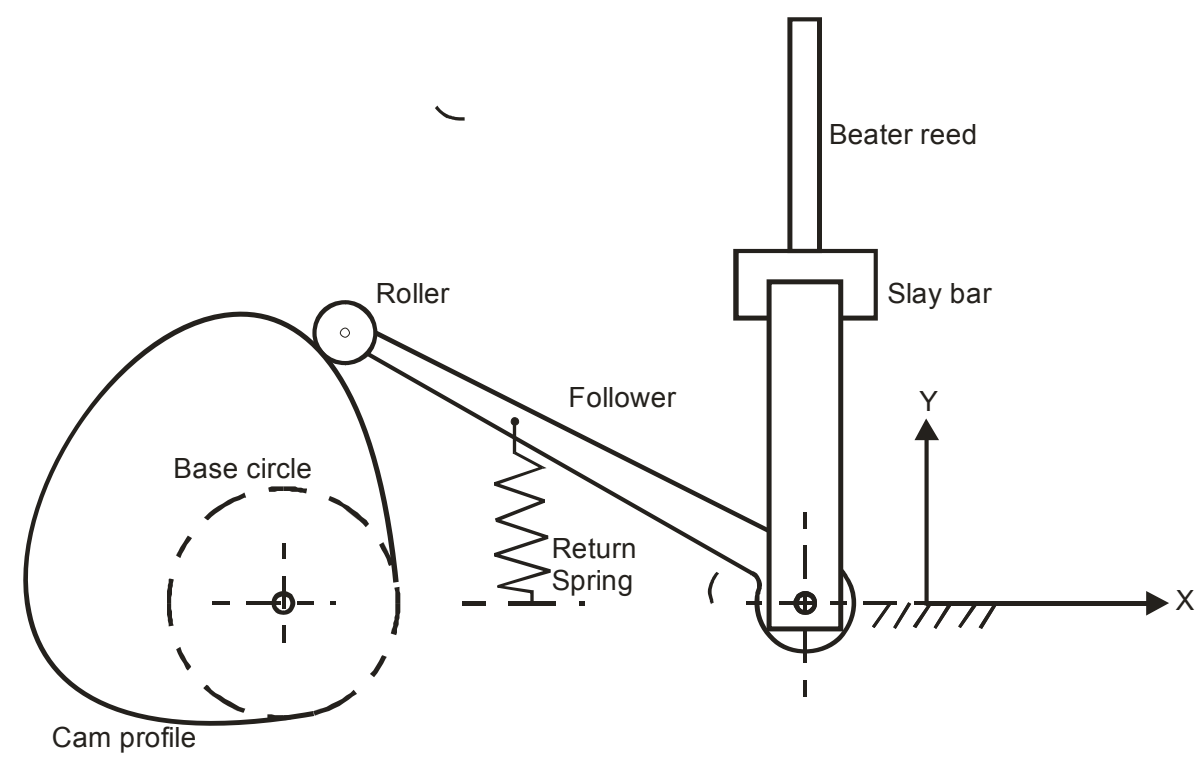

Figure 2.1 Schematic diagram of the cam-follower system for the narrow horizontal weaving loom (Raji et al., 2016) 
The beater reed is rigidly connected to the follower link at a specified angle such that the beater reed exhibits a sinusoidal motion for the beat up action of the reed on clothe weft. If the speed of the cam shaft increases rapidly, overshoot will occur and the actual speed of the cam plate, follower and beater will oscillate around the desired speed. The amplitude of oscillations increases with the speed as discussed in Raji et al., (2016) as shown in Figure 2.1. The control of the performance response of the mechanism shown in the Figure 2.2 is the focus of discuss in this paper.
DYNAMIC MODELING

The design of the control system for the mechanism requires building a mathematical model of the system. Raji et al., (2016) developed the mathematical model for the system response as expressed in equations 1-3 and for the residual vibration as expressed in equations (4-7) for the system's cam plate, follower and beater link respectively. The expressions for the dynamic response of the system were obtained from the application of the Newton's second law of motion.

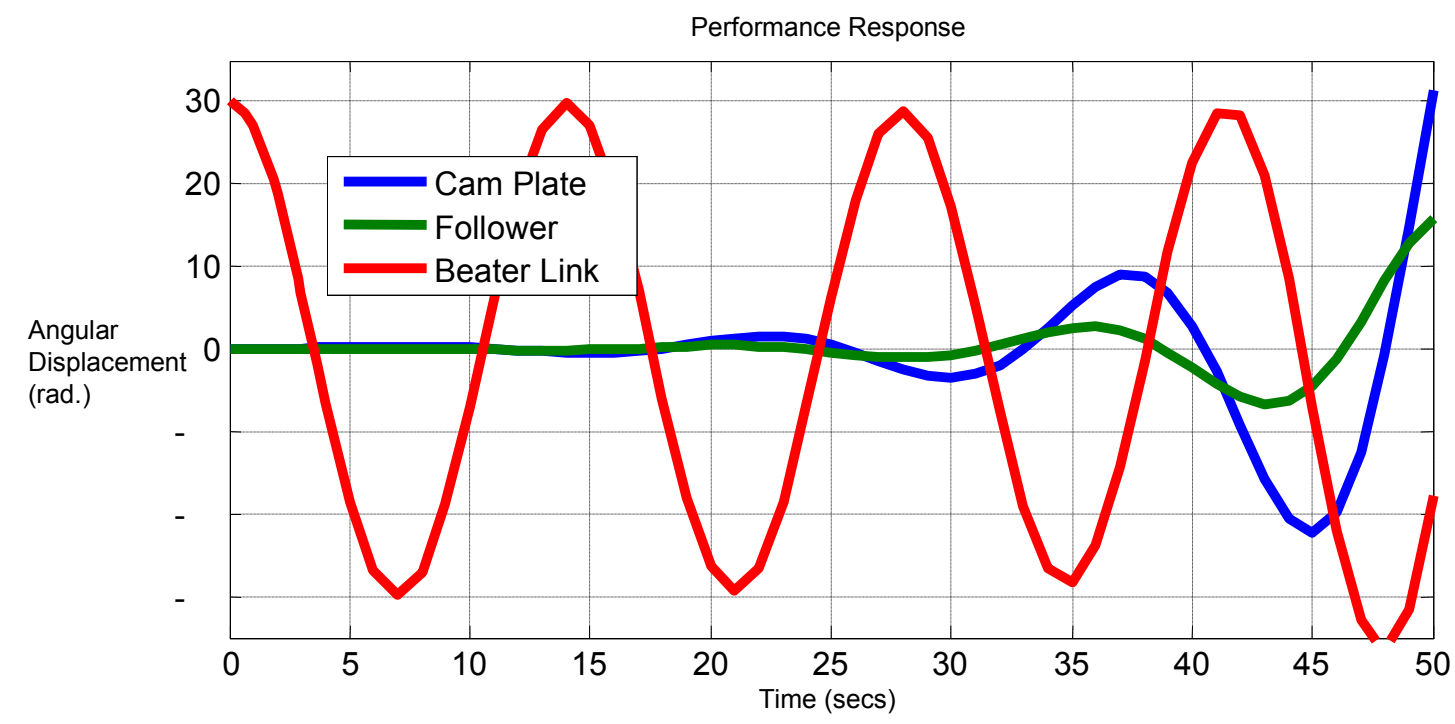

Figure 2.2 Performance response of cam swing follower mechanism for narrow loom weaving machine

(Raji et al, 2016)

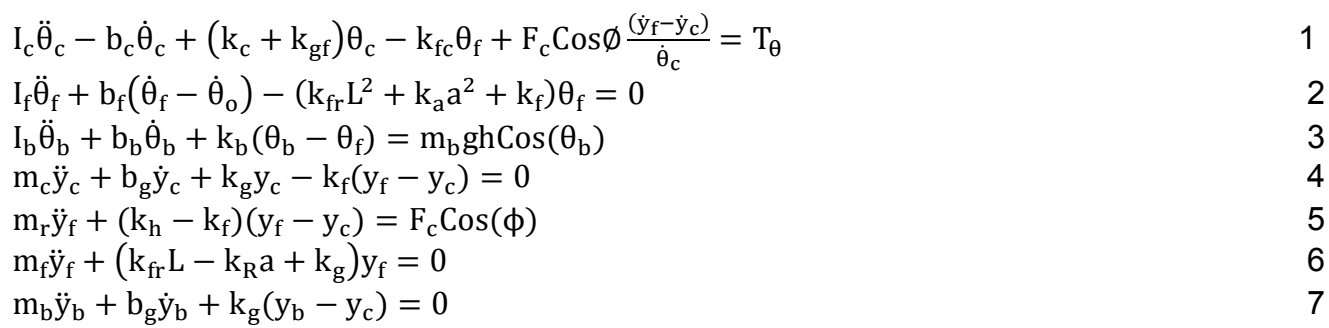

$\mathrm{F}_{\mathrm{c}}$ is the contact force between the cam and roller and could be expressed as in equation (8) as obtained in Raji et al., (2011b).

$\mathrm{F}_{\mathrm{c}}=\frac{\mathrm{I}_{\mathrm{f}} \ddot{\theta}_{\mathrm{f}}}{\mathrm{r}_{\mathrm{r}} \operatorname{Cos}(\phi)}$

$\phi$ is the pressure angle obtained as in equation (9) (Raji et al., 2011b)

$\phi=\tan ^{-1}\left[\cot \left(\theta_{\mathrm{f}}-\theta_{\mathrm{fo}}\right)-\frac{\mathrm{L}\left(1-\frac{\mathrm{d}_{\mathrm{f}}}{\mathrm{d}_{\mathrm{c}}}\right)}{\mathrm{C} \sin \left(\theta_{\mathrm{f}}+\theta_{\mathrm{fo}}\right)}\right]$

Where $L$ is the length of the roller arm,

$\mathrm{C}$ is the distance between the cam center and the follower pivot point

$\theta_{\mathrm{f}}$ is the follower angular displacement

$\theta_{\mathrm{fo}}$ is the angular follower displacement at start of motion

$\theta_{c}$ is the cam plate angular displacement 


\section{CONTROL STRATEGY}

Designing the control system for the cam follower mechanism include selection, modification, relocation of controllers and selection of suitable parameter values for the controller in order to attenuate the residual vibration of the cam-follower system output. Saranya \& Pamela, (1997); Andromeda, Yahya, Samion, Baharom \& Hashim, (2013) developed techniques suitable for determining parameters of the PID controller gains based on step response analysis. The controller parameters were tuned to achieve the necessary reduction in the residual vibration towards improving the performance of the system. The analog circuitry for the PID controller was added at suitable location in the system. The narrow loom system control required that the system be operated such that output of the system remains within certain operating condition such as allowing only for the response while eliminating in its entirety the residual responses of the system's subassemblies. The design operating range was earlier obtained in Raji et al., (2016) as obtained for equations $(1-3)$
The residual vibration needed to be controlled include the linear displacement of the cam plate, the follower link and the beater link as modeled in equations (4-7).

The objective of the system control is therefore to maintain the process at the set point of responses satisfying equations (1-3) under certain dynamic conditions as may be specified by the designer. The concept of the control system which tends to satisfy a set of performance specifications for the cam-follower system is as shown in the block diagram of Figure 2.3.

A proportional-integral-derivative (PID) controller is a generic feedback control structure widely used in industries. The PID controller involves three terms. The proportional term determines the control signal based on the current error, the integral term determines the control signal based on the integral of error, and the derivative term determines the control signal based on the derivative of error.

The controllers electronically generates the actuator signal by combining the term proportion to the error, the integral of the error and the differential of the error to obtain the actuator signal as expressed in equation 10 .

$\mathrm{u}(\mathrm{t})=\mathrm{k}_{\mathrm{p}} \mathrm{e}(\mathrm{t})+\mathrm{k}_{\mathrm{I}} \int_{0}^{\mathrm{t}} \mathrm{e}(\tau) \mathrm{d} \tau+\mathrm{k}_{\mathrm{D}} \frac{\mathrm{de}(\mathrm{t})}{\mathrm{dt}}$

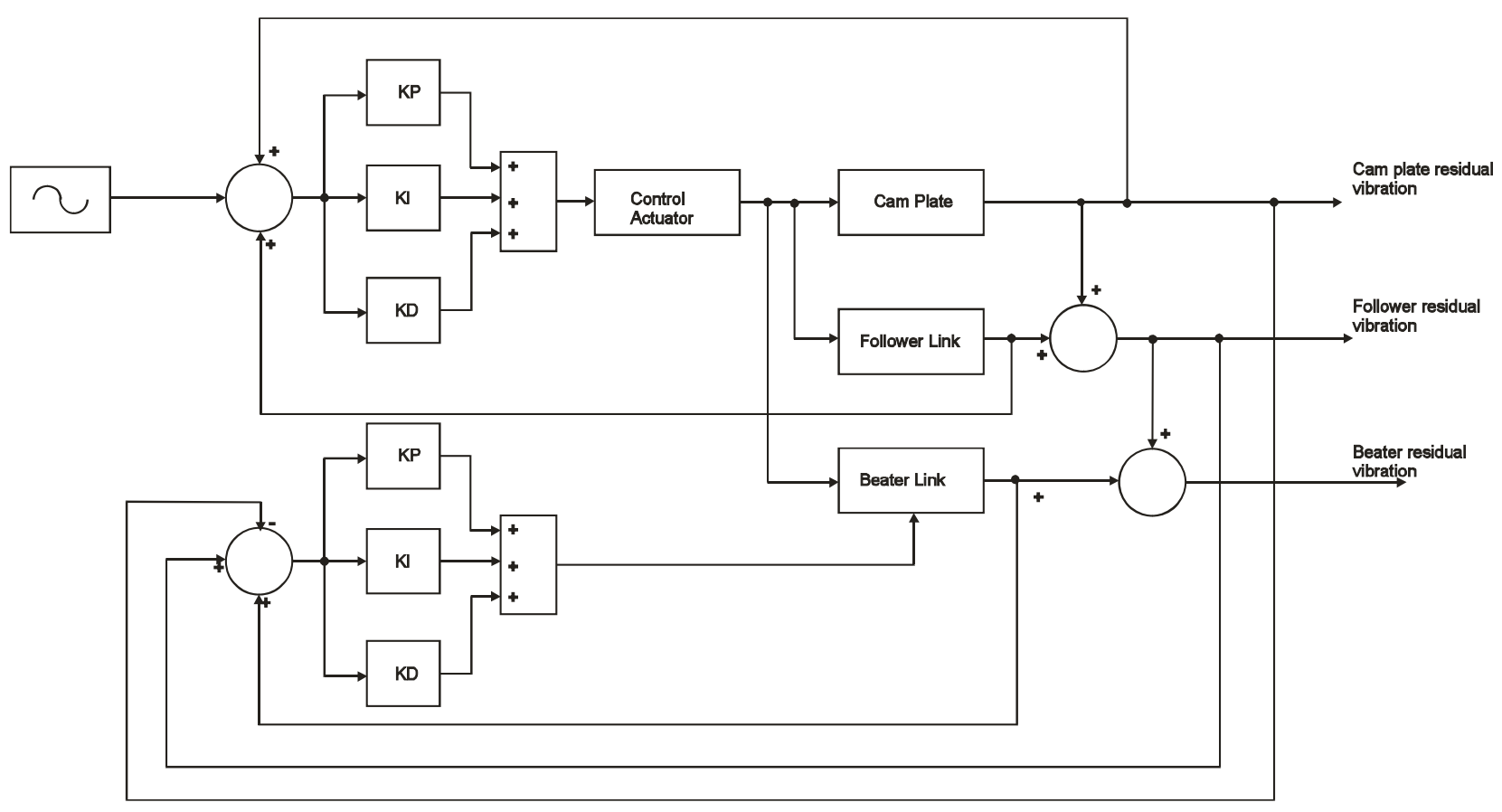

Figure 2.3 Narrow loom system control block diagram

The transfer function of the PID controller could therefore be obtained as;

$\frac{\mathrm{U}(\mathrm{s})}{\mathrm{E}(\mathrm{s})}=\mathrm{K}_{\mathrm{P}}+\frac{\mathrm{K}_{\mathrm{I}}}{\mathrm{s}}+\mathrm{K}_{\mathrm{D}} \mathrm{S}$

Where $\mathrm{K}_{\mathrm{P}}, \mathrm{K}_{\mathrm{l}}$, and $\mathrm{K}_{\mathrm{D}}$ are respectively the proportional, integral and differential controller gains.

Changes are deliberately made to the gains of the controllers, $\mathrm{K}_{\mathrm{p}}, \mathrm{K}_{\mathrm{l}}$ and $\mathrm{K}_{\mathrm{D}}$ and the output response performance and inference recorded of the extent of influence of the controller gains variation. Upon the design of the control system, it is necessary to tune the parameters in order to obtain the desired performance of the narrow loom beater system. It is a simulation process as demonstrated in SIMULINK. The tuning parameters will interact to change the controller output thus producing changes in the narrow loom subsystems response variables. 


\section{SIMULATION RESULTS}

The PID control strategy is considered having identified its ability to reduce in logarithmic mode the amplitude of the residual vibration of the cam plate, follower and beater of the narrow loom mechanism under consideration.

The curves of Figures 3.1-3.3 are the results of the use of the PID control strategy to eliminate the residual vibration during the operation of the narrow loom swing roller cam-follower mechanism. It is observed that the introduction of the controllers influences the performance of the weaving system. The figures show how the residual response of the cam plate, follower and beater were controlled to minimize the amplitude of the residual vibration which gradually decays with time.

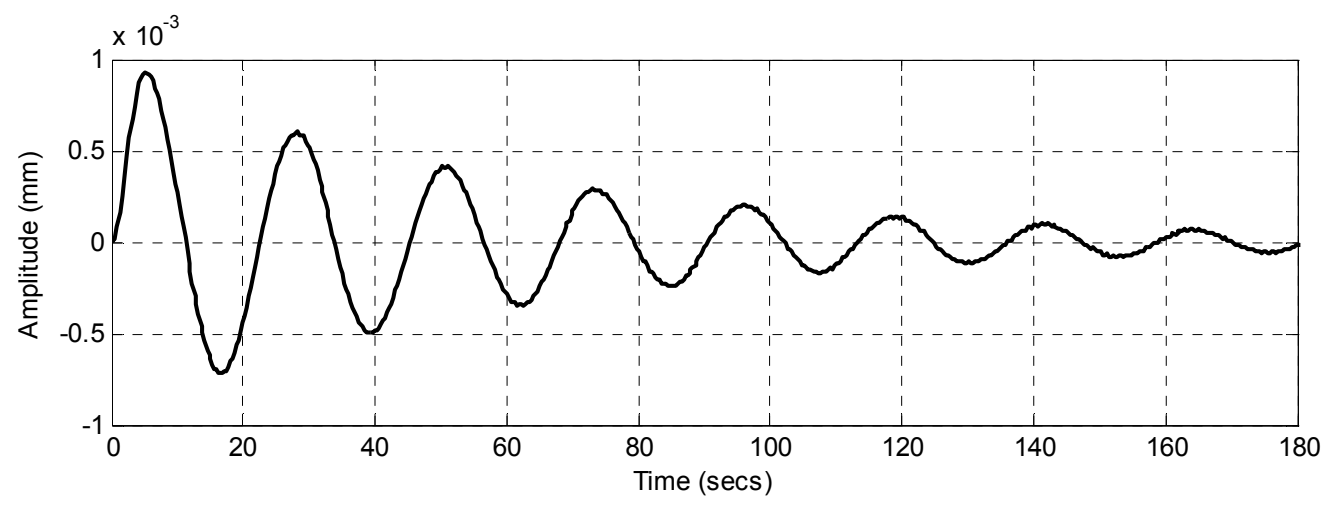

Figure 3.1 Time response curve showing the effect of addition of PID controller for reducing the residual vibration of the cam plate motion

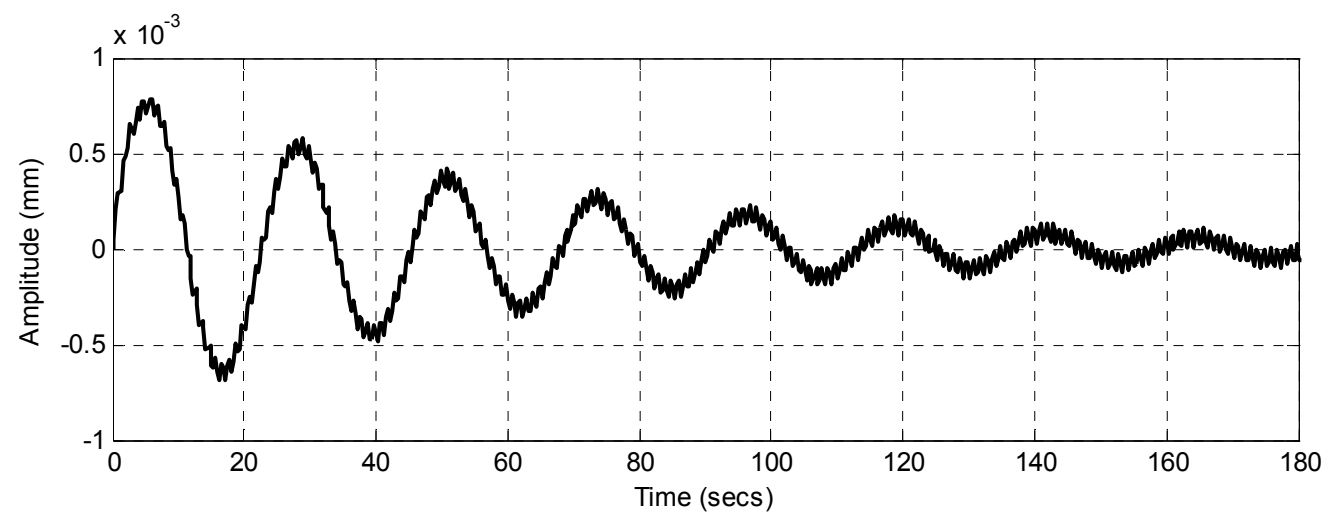

Figure 3.2 Time response curve showing the effect of addition of PID controller for reducing the residual vibration of the follower motion

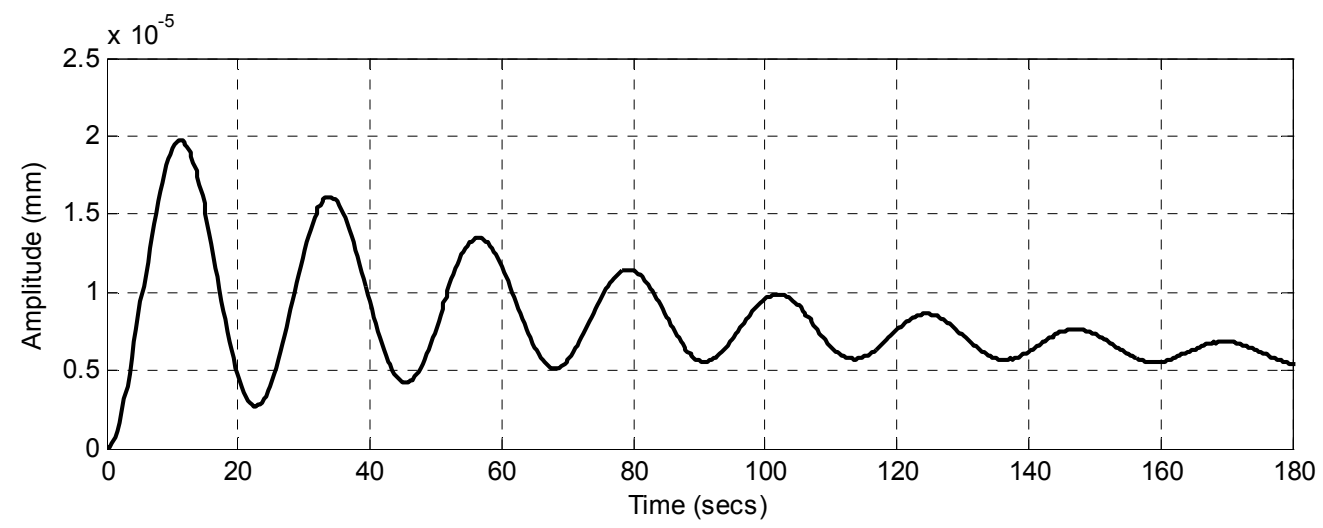

Figure 3.3 Time response curve showing the effect of addition of PID controller for reducing the residual vibration of the beater motion 
The vibration response for the cam plate (Figure 3.1) and follower (Figure 3.2) are closely related which could be as a result of the direct contact of the follower and cam which tends to demonstrate same response pattern to the input motion of the cam shaft. The successive amplitude of the residual vibration reduces as the mechanism operation progresses with time as demonstrated in the amplitude line spectrum shown in Figure 3.4. The beater has relatively low reduction rate compared to the cam plate and follower as shown in Figure 3.4 .

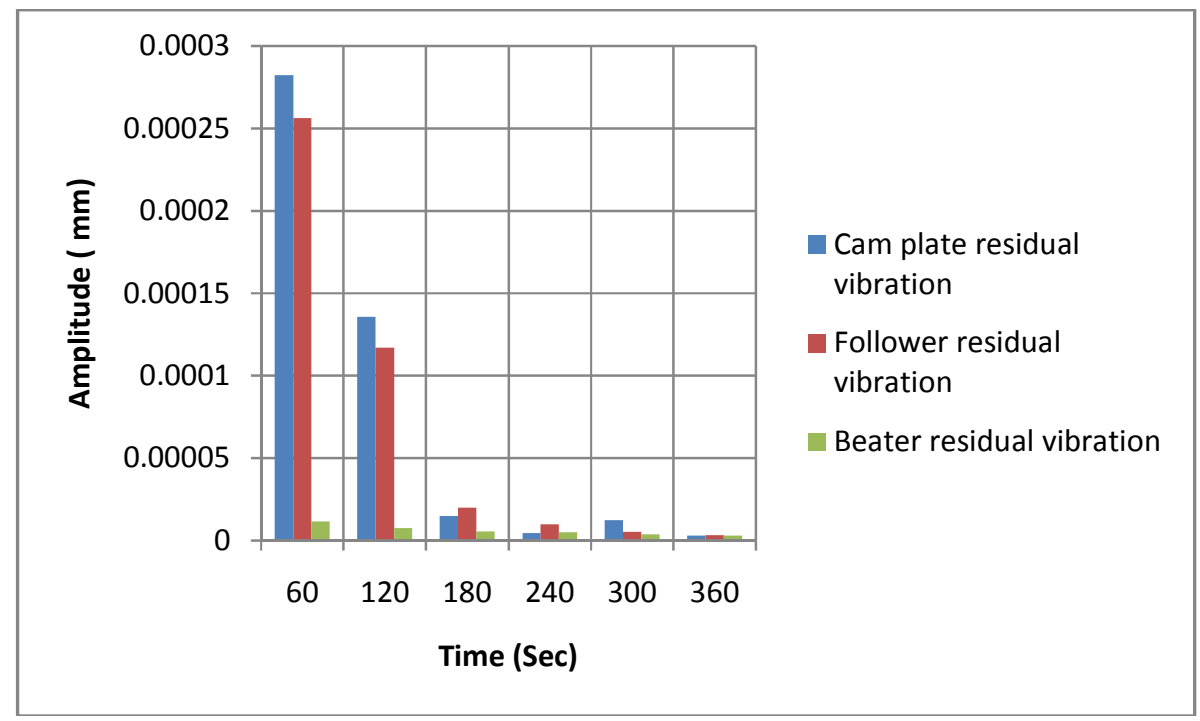

Figure 3.4 Line amplitude spectrums for the cam swing follower system

The response characteristics of the system using the PID controllers were found to depend strongly on the choice of the gain parameters $\mathrm{K}_{\mathrm{D}}$ and $\mathrm{K}_{\mathrm{l}}$. These gains are simply parameters that are contained in the control system. However the simulation explicitly exposes more the influence of the derivative gains on the logarithmic decrement of the cam plate and follower. The proportional gain $\left(\mathrm{K}_{\mathrm{P}}\right)$ of the control strategy had very little influence on the attenuation of the residual vibration of the system. Values could therefore be selected for these parameters to reduce the amplitude of the residual vibration as the operation of the mechanism progresses with time in response to the input cam shaft speed.

\section{CONCLUSION}

The PID controller was designed to reduce the existing residual vibration of nonlinear nature in a swing roller follower cam mechanism. The cam mechanism was earlier designed to generate the beatup motion for a narrow loom weaving machine. The introduction of the PID controllers was able to achieve desirable dynamical behavior for the loom. The control procedure include locating the PID controllers at preferable points in the mechanism to serve as feed-forward devices regulating the feedback mechanism output signals and also changing of the parameter values of the controller gains and monitoring the amplitude spectrum of the residual vibration in response to the change in controller gains values.

\section{REFERENCES}

Abu-Mahfouz, I., and Badrakhan, F., 1990. Chaotic behaviour of some piecewise-linear systems part I: Systems with set-up spring or with unsymmetric elasticity. Journal of Sound and Vibration, 143(2),

255288. https://doi.org/10.1016/0022460X(90)90954-X

Abu-Mahfouz, I., and Badrakhan, F., 1990b. Chaotic behaviour of some piecewise-linear systems, part II: Systems with clearance. Journal of Sound and Vibration, 143(2), 289328. https://doi.org/10.1016/0022460X(90)90955-Y

Aguilar-Lopez R. and Martinez-Guerra R., 2007. Partial synchronization of different chaotic oscillators using robust PID feedback. Chaos, Solit. and Fract., 33(2), 572-581. doi:10.1016/j.chaos.2005.12.042

Ahirrao N. S and Khond V. V., 2012. Cam dynamics and vibration control by detecting jump. International Journal of Research in Engineering and Applied Sciences, 2(2), 1413-1422. 
Andromeda T., Yahya A., Samion S., Baharom A. and Hashim N., 2013. PID Controller Tuning by Differential Evolution Algorithm on EDM Servo Control System, Applied Mechanics and Materials, 284-287. 2266-2270. doi.org/10.4028/www.scientific.net/AMM.284287.2266.

Coelho L. S. and Bernert D. L. A., 2009. PID control design for chaotic synchronization using a tribes optimization approach. Chaos, Solit. and Fract., $42 \quad(1)$, 634-640. doi.org/10.1016/j.chaos.2009.01.032.

Ebrahim N.D., 2006. Optimal vibration abatement of mechanical systems. Earthquake Engineering and Structural Dynamics, 18(8), 1179-1187. doi.org/10.1002/eqe.4290180405.

Esfandiari, R.S. and Lu, B., 2018. Modeling and analysis of dynamic systems (3rd ed.). New York, CRC Press taylor and Francis Group.

Gatti G, Mundo D and Danieli G., 2007. A combined feedforward and feedback control strategy to improve the dynamic performance of camfollower system. $12^{\text {th }}$ IFTMM World Congress, Besençon (France), June 18-21.

Hirose, N., Kawafuku, M., Iwasaki, M. and Hirai, H., 2006. Residual vibration suppression using initial value compensation for repetitive positioning. Electrical Engineering in Japan, 157(3), 63-72. DOI:10.1002/eej.20276

Hou Y-Y., 2017. Design and implementation of EPbased PID controller for chaos synchronization of Rikitake circuit systems. ISA Transactions, 70. 260-268. doi.org/10.1016/j.isatra.2017.04.016i.

Kuo C. L., Yau H. T., and Pu Y. C., 2008. Design and implementation of a digital PID controller for a chaos synchronization system by evolutionary programming. Journal of Applied Sciences, 8. 2420-2427. Doi: 10.3923/jas.2008.2420.2427.

Nandy $U$ and Sengupta S. N., 1996. Minimization of residual vibrations in lumped parameter positioners-a non-time-optimal bang-bang control. Journal of Sound and Vibration, 196(3). 263-274. doi.org/10.1006/jsvi.1996.0482.

Raji, N. A., 2000. Motion Specification for Beat-Up Mechanism of Narrow Horizontal weaving Loom. Annals of Engineering Analysis. 1(2). 2840.
Raji, N. A. and Adegbuyi, P. A. O., 2003. Synthesis of Cam Follower System for the Beater Mechanism of a Narrow Horizontal Loom. Nigerian Journal of Mechanical Engineering, 1(1). 37-48.

Raji, N. A, Erameh, A. A. Ozor, V. O., Ajayi, F. O. and Kuku, R. O., 2010. Modeling Narrow loom Beatup System with Cam Transmission Influence. Journal of Engineering and Applied Sciences 5(3). 206-210. Doi:10.3923/jeasci.2010.206.210

Raji, N. A, Ozor, V. O. and Kuku, R.O., 2011a. Camfollower mechanism design for narrow loom beat-up motion. Global journal of engineering research. $10(1 \& 2)$. 49-56.

Raji, N. A, Erameh, A. A., Ajayi, F.O. and Kuku, R.O., 2011b. Impact Analysis of Narrow Loom Beatup Mechanism. Research Journal of Applied Sciences, Engineering and Technology 3(9). 923-927.

Raji, N. A., Durojaye, R. O. and Yussouff, A.A., 2016. Dynamic modeling and sensitivity analysis of cam swing-roller follower system. International Journal of Scientific and Engineering Research, 7(5). 304-319.

Saranya, M. and Pamela, D., 2012. A Real Time IMC Tuned PID Controller for DC Motor. International Journal of Recent Technology and Engineering, 1(1). 65-70.

Singhose, W., 2009. Command Shaping for Flexible Systems: A Review of the First 50 Years. International Journal of Precision engineering and Manufacturing, 10(4). 153-168. Doi 10.1007/s12541-009-0084-2.

Tsuji, H, Itoh, H, Ogasawara, Y. and Mitsuta, S., 1995. Vibration control by optimal trajectory with feedback system. JSME International Journal, Series C, 38 (4). 663-669. doi.org/10.1299/jsmec1993.38.663.

Veciana, J. M. and Cardona, S., 2012. Residual vibration reduction in mechanical systems: A time-domain approach. International Journal of Precision Engineering, 13(8). 1327-1339. DOI: 10.1007/s12541-012-0176-2.

Yau, H. T, Hung, T. H. and Hsieh C. C., 2012. Bluetooth Based Chaos Synchronization Using Particle Swarm Optimization and Its Applications to Image Encryption. Sensors, 12. 7468-7484. doi:10.3390/s120607468 